\title{
On the Origin of Electrodeposition Mechanism of ZnO on ITO Substrate
}

\author{
Jaeyoung Lee ${ }^{\dagger}$, Sang Cheol Nam* and Yongsug Tak** \\ Fuel Cell Research Center, Korea Institute of Science and Technology, Seoul 136-791, Korea \\ *Microcell Center, Nuricell Inc., Seoul 131-220, Korea \\ **Department of Chemical Engineering, Inha University, Inchon 402-751, Korea \\ (Received 20 August $2004 \cdot$ accepted 28 October 2004)
}

\begin{abstract}
Zinc oxide ( $\mathrm{ZnO})$ was potentiostatically deposited on indium tin oxide (ITO) substrates. Comparing of the theoretical mass/charge ratio with experimental value measured by in-situ electrochemical quartz crystal microbalance, the origin of deposition mechanism of $\mathrm{ZnO}$ could be explained as follows: (i) surface $\mathrm{pH}$ enhancement due to the adsorption of hydroxide ion; (ii) the formation of intermediate species (i.e., zinc hydroxide $\left(\mathrm{Zn}(\mathrm{OH})^{+}\right)$; (iii) $\mathrm{ZnO}$ deposition with production of water. Ex-situ morphological and structural analyses by scanning electron microscope and X-ray diffraction strongly supported the deposition mechanism of $\mathrm{ZnO}$. This also showed that hexagonal shaped $\mathrm{ZnO}$ islands were first formed on ITO cathode and grew into compact $\mathrm{ZnO}$ films, and the formation behaviour of $\mathrm{ZnO}$ was clearly explained via analysis of the profile of measured current.
\end{abstract}

Key words: ZnO, Electrodeposition, Mechanistic Origin, in-situ Mass Change, Growth Mode, Conducting Characteristics

\section{INTRODUCTION}

Of late, electrochemical deposition of metal oxides such as $\mathrm{Cu}_{2} \mathrm{O}$ [Golden et al., 1996; Jongh et al., 2000; Bohannan et al., 1999; Lee et al., 2002; Oh et al., 2004], $\mathrm{PbO}_{2}$ [Vatistas et al., 2000; Lee et al., 2000], $\mathrm{Y}_{2} \mathrm{O}_{3}$ [Lee et al., 1999] and $\mathrm{ZnO}$ [Itzaki et al., 2000; Peulon et al., 1998; Lee et al., 2001; Gu et al., 1999] has been receiving increasing attention due to the following reasons: (a) thickness and morphology of films can be precisely controlled by adjusting electrochemical parameters such as current or potential, (b) relatively uniform and compact thin films can be formed onto substrates of complex shapes or into column shaped material, (c) higher deposition rates can be easily obtained over conventional processing, and (d) the equipment required is inexpensive owing to the non-requirement of either high vacuum or high reaction temperature.

$\mathrm{ZnO}$ is an n-type semiconductor with a band gap of $3.2 \mathrm{eV}$ and transparent metal oxide. It can be applied in ultraviolet-emitting diodes, piezoelectric devices, electron-field emitters, heterogeneous catalyst for methanol synthesis and short wavelength electro-optical devices [Zheng et al., 2002; Wang et al., 2003; Suh et al., 2002; Kim et al., 2004]. Up to now, $\mathrm{ZnO}$ from various electrolytes was well electrodeposited by different electrochemical methods. However, only a few studies of electrodeposition mechanism of $\mathrm{ZnO}$ have been reported. Izaki et al. [2000] studied the effect of cathodic current density and concentration on the structure of $\mathrm{ZnO}$ films. They suggested that the $\mathrm{pH}$ increased due to the reduction of nitrate ion giving rise to the precipitation of zinc hydroxide, and the following dehydration reaction induced the formation of $\mathrm{ZnO}$. On the other hand, Peulon et al. [1998] investigated the electrodeposition of $\mathrm{ZnO}$ film in zinc chloride solutions and the effects of solution temperature and local $\mathrm{pH}$ changes during the formation of $\mathrm{ZnO}$ film. They presented that the growth of film was related to the fast

To whom correspondence should be addressed.

E-mail: jaeyoung@kist.re.kr precipitation-dissolution processes and well crystallized $\mathrm{ZnO}$ films could be obtained above $50{ }^{\circ} \mathrm{C}$. We studied the effect of dissolved oxygen on the deposition rate of $\mathrm{ZnO}$ in our previous work [Lee et al., 2001] and it sufficiently increased local $\mathrm{pH}$ of the substrate, which gave rise to three times higher growth rate of $\mathrm{ZnO}$ film compared to that in oxygen-free electrolyte. More recently, Gu et al. [1999] showed that the growth rate of $\mathrm{ZnO}$ film was affected by substrate material.

In this work, we tried to understand mechanistic origin of $\mathrm{ZnO}$ electrochemical deposition by using in-situ electrochemical quartz crystal microbalance (EQCM) technique incorporated with morphological and structural analysis. Conducting characteristics and different growth modes of $\mathrm{ZnO}$ on ITO substrate were also discussed.

In the EQCM, the equation of the resonant frequency change for mass change has been presented by the well-known Sauerbrey equation [Buttary et al., 1992]

$$
\Delta \mathrm{f}=-2 \mathrm{f}_{0}^{2} \cdot \Delta \mathrm{m} / \mathrm{A}\left(\mu_{q} \rho_{q}\right)^{1 / 2},
$$

where $\mathrm{f}_{0}$ is the resonant frequency of the quartz $(9 \mathrm{MHz})$; A represents the electrode area $\left(0.196 \mathrm{~cm}^{2}\right) ; \mu_{q}$ is the shear modulus of quartz $\left(2.947 \times 10^{11} \mathrm{~g} \mathrm{~cm}^{-1} \mathrm{~s}^{-2}\right) ; \rho_{q}$ is the density of quartz $\left(2.648 \mathrm{~g} \mathrm{~cm}^{-3}\right)$. Eq. (1) can be simplified as

$$
\Delta \mathrm{f}=-\mathrm{C}_{f} \Delta \mathrm{m} \text {, }
$$

in which $\mathrm{C}_{f}(935.7 \mathrm{~Hz} / \mu \mathrm{g})$ is a constant solely determined by the properties of the quartz crystal.

\section{EXPERIMENTAL}

$\mathrm{ZnO}$ was electrochemically deposited onto ITO substrate. The geometric area of the electrode was $0.196 \mathrm{~cm}^{2}$. Prior to experiments, AT-cut ITO quartz crystal (Seiko Instruments Inc.) was thermally treated at $500^{\circ} \mathrm{C}$ for $2 \mathrm{hrs}$ to reduce the resistance and was ultrasonically cleaned with acetone solution in order to remove organic 
residue. While BT-cut, CT-cut, DT-cut and NT-cut could only be used at $29^{\circ} \mathrm{C}$, AT-cut quartz crystal could be used in a wide range of temperature between $-20^{\circ} \mathrm{C}$ and $+75^{\circ} \mathrm{C}$, ignoring the relationship of frequency and temperature variation. Counter electrode was $\mathrm{Zn}$ plate in order to maintain the same concentration with $\mathrm{Zn}^{2+}$ of bulk solution, and a saturated calomel electrode (SCE) was employed as a reference electrode. $0.1 \mathrm{M} \mathrm{Zn}\left(\mathrm{NO}_{3}\right)_{2}$ (Aldrich, $99.99 \%$ ) solution was prepared with ultra-pure water (Millipore, $18.2 \mathrm{M} \Omega \cdot \mathrm{cm}$ ). The $\mathrm{pH}$ of initial solution was 5.2 and solution temperature was adjusted to $60^{\circ} \mathrm{C}$.

Electrodeposition was executed at constant potential mode (chronoamperometry) and the mass change of ITO cathode was measured by means of in-situ EQCM (Seiko EG\&G QCA917). The morphology and crystal structure of deposited $\mathrm{ZnO}$ film were observed with scanning electron microscope (SEM, Hitachi S-4200) and X-ray diffraction (XRD, Phillips DY616).

\section{RESULTS AND DISCUSSION}

Hydroxide ions produced by reduction of nitrate ion and dissolved oxygen (see Eqs. (3) and (4)) usually increase local $\mathrm{pH}$ of ITO substrates. As a result, zinc hydroxide $\left(\mathrm{Zn}(\mathrm{OH})^{+}\right)$is formed near ITO surface (Eq. (5)). Then, as an initial stage of growth, hexagonal-shaped $\mathrm{ZnO}$ islands are formed on the ITO substrate (Eq. (6)).

$$
\begin{aligned}
& \mathrm{NO}_{3}^{-}+\mathrm{H}_{2} \mathrm{O}+2 \mathrm{e}^{-} \rightarrow \mathrm{NO}_{2}^{-}+2 \mathrm{OH}^{-}, \\
& \mathrm{O}_{2}+2 \mathrm{H}_{2} \mathrm{O}+4 \mathrm{e}^{-} \rightarrow 4 \mathrm{OH}^{-}, \\
& \mathrm{Zn}^{2+}+\mathrm{OH}^{-}+* \rightarrow \mathrm{Zn}(\mathrm{OH})_{a d}^{+} / \mathrm{ITO} \\
& \mathrm{Zn}(\mathrm{OH})_{a d}^{+} / \mathrm{ITO}+\mathrm{OH}^{-} \rightarrow \mathrm{ZnO}+\mathrm{H}_{2} \mathrm{O},
\end{aligned}
$$

where $*$ and subscript ${ }_{a d}$ indicate the vacancy site of the surface and the adsorption on the surface.

Fig. 1 shows cathodic scan of ITO electrode in oxygen-saturated zinc nitrate solution with scan rate of $20 \mathrm{mV} / \mathrm{s}$. Current plateau with irregular current oscillations was obtained between $-0.45 \mathrm{~V}$ and -0.95 $\mathrm{V}$ and the potential of $-0.72 \mathrm{~V}$ considered as appropriate value for $\mathrm{ZnO}$ electrodeposition was obtained. In the next step, the mechanistic origin of $\mathrm{ZnO}$ formation on ITO substrate would be investigated.

Figs. $2 \mathrm{a}$ and $2 \mathrm{~b}$ show in-situ mass shift curve and current den-

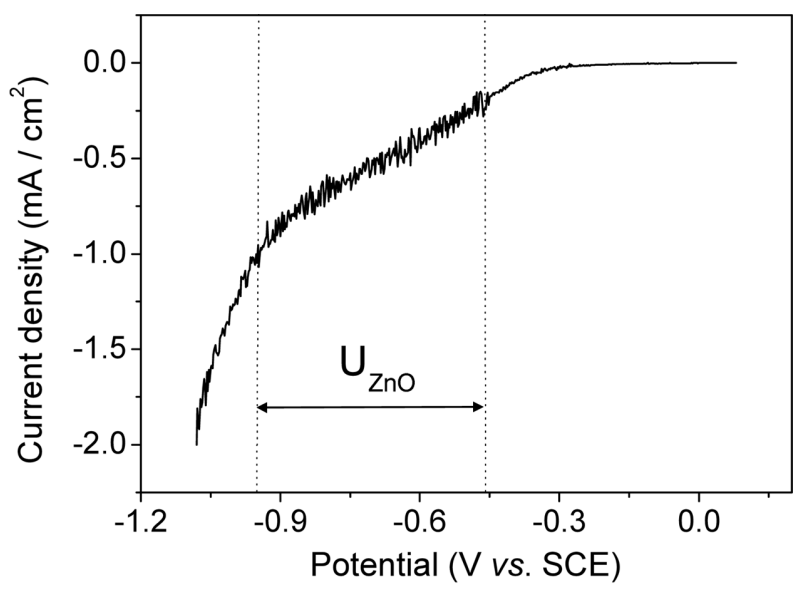

Fig. 1. Current/potential profile of the cathodic scan with scan rate of $20 \mathrm{mV} / \mathrm{s}$ in $0.1 \mathrm{M} \mathrm{Zn}\left(\mathrm{NO}_{3}\right)_{2}$ at $60{ }^{\circ} \mathrm{C}$.

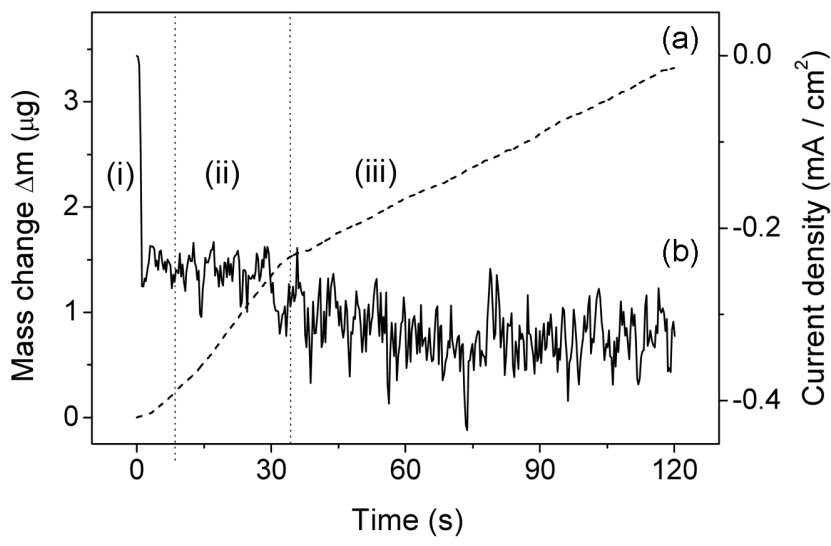

Fig. 2. (a) In-situ mass change and (b) chronoamperometric curves during the electrodeposition of $\mathrm{ZnO}$ in the constant potential of $-0.72 \mathrm{~V}$ at $60^{\circ} \mathrm{C}$.

sity profile at $-0.72 \mathrm{~V}$. Mass of the substrate is changed with three different rates, indicating the adsorption of hydroxide ion, the precipitation of zinc hydroxide, and the deposition of $\mathrm{ZnO}$. In region (i), small mass increase of $0.015 \mu \mathrm{g}$ is observed for initial $2.5 \mathrm{~s}$ due to the adsorption of hydroxide ions of ca. $1 \times 10^{-4} \mathrm{M}$. We assume that adsorbed hydroxide ions increase local $\mathrm{pH}$ of ITO surface from 5.2 to over 10 and induce the preferred formation of zinc hydroxide $\left(\mathrm{Zn}(\mathrm{OH})^{+}\right)$(pls. refer to Refs. [Peulon et al., 1998; Izaki et al., 2000; Lee et al., 2001]). Note that intermediate species, i.e., zinc hydroxide could be formed over $\mathrm{pH} 10$ according to Pourbaix diagram and reaction (5) and exists as stable state, $\mathrm{Zn}(\mathrm{OH})^{+}$. As a result, the surface mass significantly increases in region (ii) and the slope of linear curve in region (ii) represents that $\Delta \mathrm{m} / \Delta \mathrm{Q}$ is $0.851 \mathrm{mg} / \mathrm{C}$. It is in good agreement with the theoretical value of $0.855 \mathrm{mg} / \mathrm{C}$ for the formation of $\mathrm{Zn}(\mathrm{OH})^{+}$. In addition, the result supports $\mathrm{Zn}(\mathrm{OH})^{+}$ ion be a reaction intermediate. On the other hand, in region (iii), experimental mass/charge ratio $(\Delta \mathrm{m} / \Delta \mathrm{Q})$ is $0.377 \mathrm{mg} / \mathrm{C}$ which is slightly smaller than the theoretical value of $0.420 \mathrm{mg} / \mathrm{C}$. The difference of mass/change ratio could be originating from water production (see Eq. (6)).

Unlike mass change, cathodic current shows complicated responses

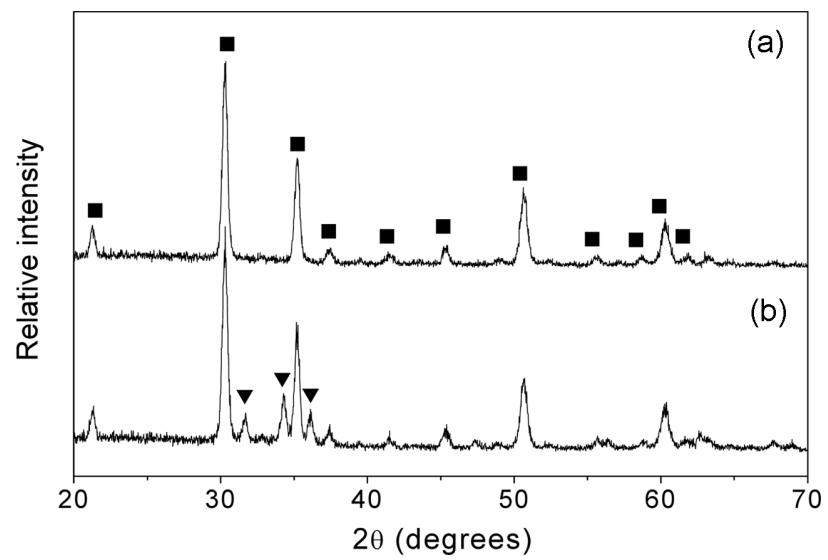

Fig. 3. X-ray diffraction data of deposited material on ITO. (a) $15 \mathrm{~s}$ and (b) $2 \mathrm{~min}$. Square and reversed triangle indicate the peaks originated from ITO and $\mathrm{ZnO}$, respectively. 
which might be due to the following two reasons: (i) non-uniform local $\mathrm{pH}$ was formed onto and/or near the ITO substrate; (ii) the growth mode of $\mathrm{ZnO}$ could continuously change active surface areas. However, detailed reasons of complex current responses are not clear yet and thus, further studies should be performed.

The structure and morphology of $\mathrm{ZnO}$ film formed onto ITO substrate are analyzed by XRD and SEM techniques. Fig. 3(a) shows the XRD data of deposited material on the ITO for initial $15 \mathrm{~s}$ (see region (ii) of Fig. 2). From that, there is no crystalline phase, indicating $\mathrm{ZnO}$ formation. As mentioned above, $\mathrm{OH}^{-}$generated by reaction (1) only results in the $\mathrm{pH}$ increase on the ITO electrode surface and makes unstable intermediate species, $\mathrm{Zn}(\mathrm{OH})^{+}$. Therefore, we could observe only a peak corresponding to ITO substrate. The structural measurement of deposited material after electrolysis time of $120 \mathrm{~s}$ is shown in Fig. 3(b) and several new phases (closed triangle) are detected on the ITO substrate, indicating the formation of $\mathrm{ZnO}$.

The nucleation of $\mathrm{ZnO}$ islands formed in initial state of growth is shown in Fig. 4(a). The growth of initial $\mathrm{ZnO}$ islands and new nucleation increase the density of $\mathrm{ZnO}$ islands and then, coalescence of adjacent islands is observed in Fig. 4(b).

These SEM and XRD analyses strongly support the origin of electrodeposition of $\mathrm{ZnO}$ with the result of mass/charge pattern by EQCM.
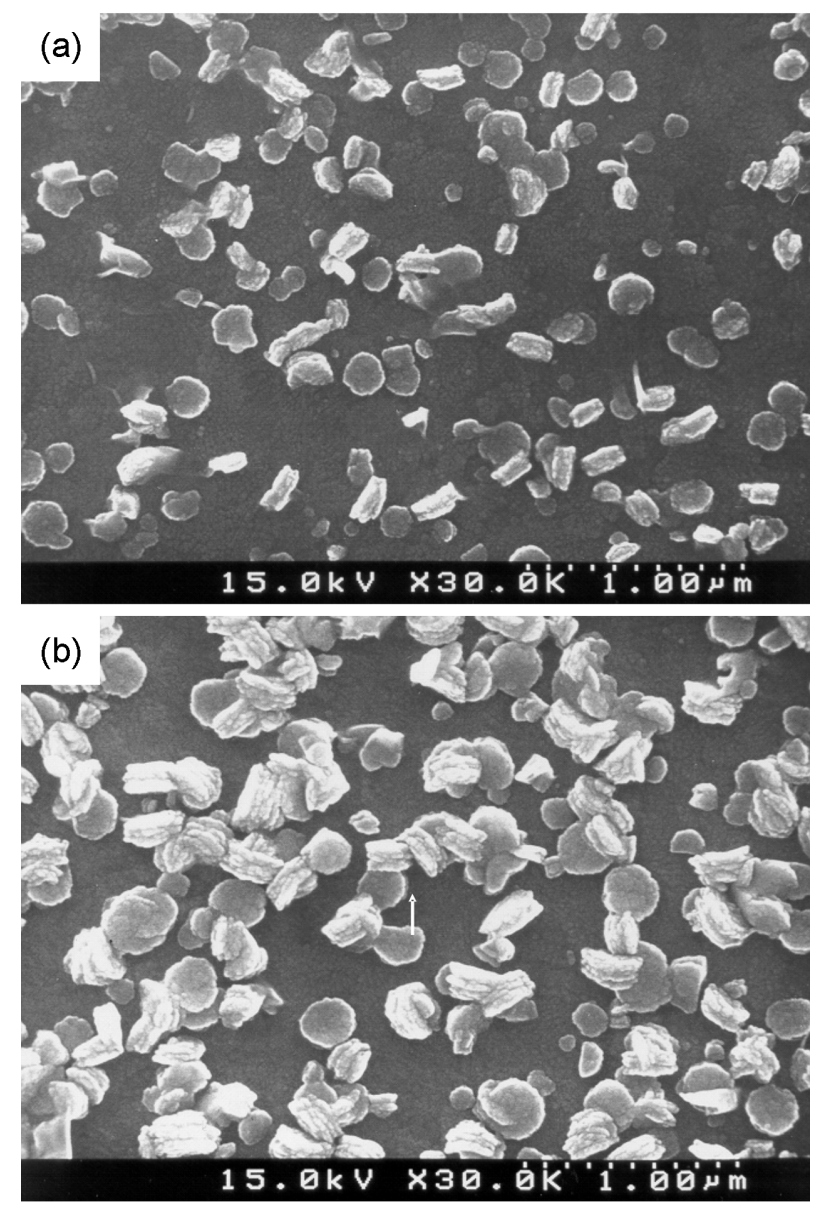

Fig. 4. Scanning electron microscope images of $\mathrm{ZnO}$ on ITO in cathodic potential of $-0.72 \mathrm{~V}$ at $60^{\circ} \mathrm{C}$. (a) $1 \mathrm{~min}$ and (b) 2 min.
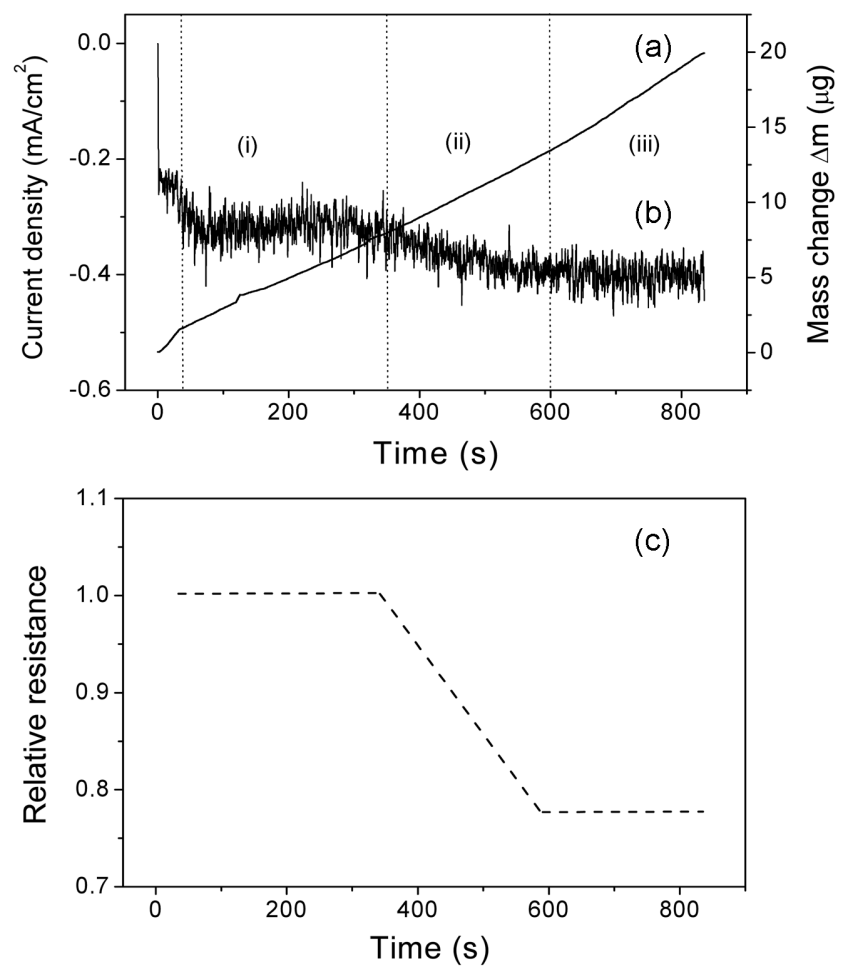

Fig. 5. (a) Mass change, (b) current curve and (c) the relative resistance during the electrodeposition of $\mathrm{ZnO}$ in the applying constant potential of $-0.72 \mathrm{~V}$ at $60^{\circ} \mathrm{C}$. The relative resistance is obtained by Ohm's law.

In the faster mass/charge ratio of region (ii) in Fig. 2, the incorporation of zinc ion is performed into adsorbed hydroxide ion on the ITO substrate. Relatively slower mass change rate of region (iii) in Fig. 2 relates to the $\mathrm{ZnO}$ deposition.

In direct current (D.C.) theory, resistance is defined by Ohm's Law (U=IR). And then, the resistance $(\mathrm{R})$ by measuring the current (I) under applied constant potential (U) was calculated. Figs. 5(a) and 5(b) show the surface mass change and the resulting current, respectively, when constant cathodic potential of $-0.72 \mathrm{~V}$ is applied. Three distinct current profiles and surface mass changes are obtained. In region (I), the average value of current density of -0.3 $\mathrm{mA} / \mathrm{cm}^{2}$ is obtained, while faster current density of $-0.4 \mathrm{~mA} / \mathrm{cm}^{2}$ is observed in region (III). By calculating the mass/time, the higher deposition rate of $1.70 \mu \mathrm{g} / \mathrm{min}$ in region (III) was obtained, compared with $1.25 \mu \mathrm{g} / \mathrm{min}$ in region (I). Fig. 5(c) shows relative resistance with linear current and constant potential of $-0.72 \mathrm{~V}$. If initial resistance is assumed as $100 \%$, only $77 \%$ of total resistance would be obtained after the formation of $\mathrm{ZnO}$ film. This result implies that $\mathrm{ZnO}$ film deposited is a better cathodic material compared with ITO substrates.

Considering the increase of cathodic current shown in Fig. 5(a), one might assume that $\mathrm{ZnO}$ deposition undergoes two different growth modes. In order to clearly prove this assumption, morphological analysis is conducted. Fig. 6(a) and 6(b) are SEM images of ZnO/ITO in the electrolysis time of $10 \mathrm{~min}$ and $60 \mathrm{~min}$, respectively. Throughout the transition region (II), islanding growth mode of $\mathrm{ZnO}$ on ITO is changed into bulk deposition of $\mathrm{ZnO}$ with uniform thickness. Fig. 6(a) shows a surface image of uniformly grown $\mathrm{ZnO}$ film. $\mathrm{ZnO}$ films 


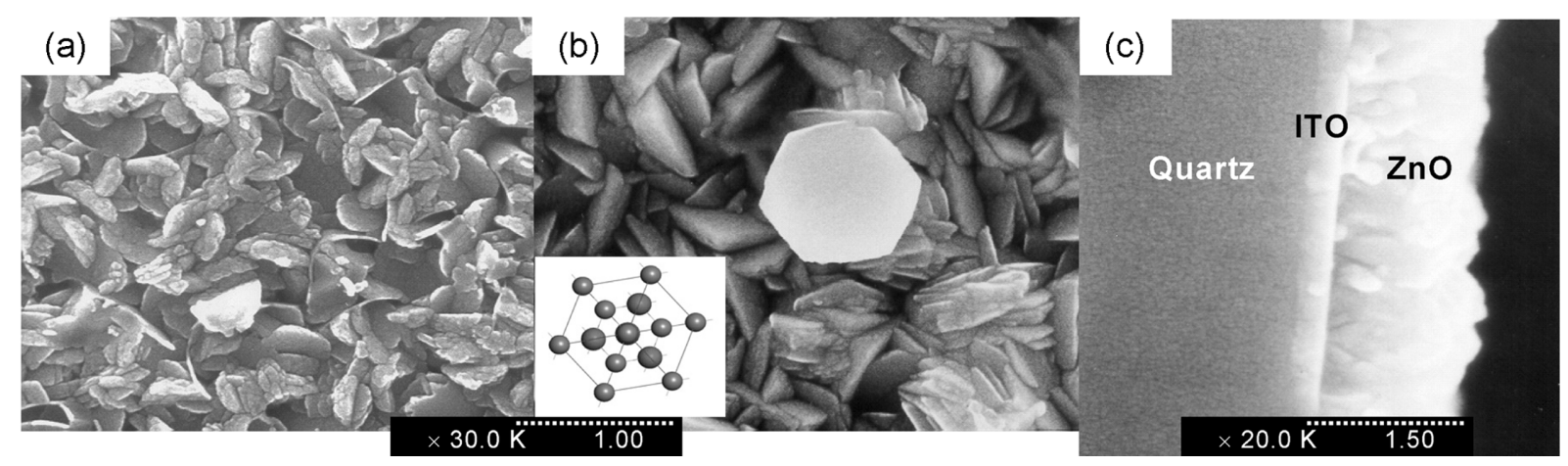

Fig. 6. Morphological changes of deposited materials in different electrolysis time in the applying constant potential of $-0.72 \mathrm{~V}$ at $60{ }^{\circ} \mathrm{C}$. (a) $10 \mathrm{~min}$, (b) $60 \mathrm{~min}$ and (c) cross-section of (b). Inset shows zinc blended structure.

are compact structure with distinct hexagonal-shaped islands and single crystal size is about $0.8 \mu \mathrm{m}$ (see Fig. 6(b)). From cross-sectional SEM image (Fig. 6(c)), one can clearly see three different layers, bare quartz crystal, ITO substrate, and $\mathrm{ZnO}$ films deposited without any defect (or hole) during growing. The growth rate of $\mathrm{ZnO}$ film is $0.2 \mu \mathrm{m} / \mathrm{min}$.

\section{CONCLUSIONS}

We investigated electrodeposition mechanism of $\mathrm{ZnO}$ by in-situ EQCM and ex-situ surface and structural analyses. First, different slopes of mass/charge ratio at different electrolysis time by using insitu EQCM were obtained and indicated that $\mathrm{ZnO}$ could be formed during the production of water via intermediate species of $\mathrm{Zn}(\mathrm{OH})^{+}$. In addition, we observed a change of the growth mode; $\mathrm{ZnO}$ islands were initially formed on the ITO substrate and $\mathrm{ZnO}$ thin film was growing toward bulk deposition with faster deposition rate. Analyzing the current profile in the $\mathrm{ZnO}$ deposition under constant potential, we clearly demonstrated that the deposited $\mathrm{ZnO}$ has relatively lower resistance, compared to that of ITO cathode. After the formation of $\mathrm{ZnO}$ film on ITO cathode, about $23 \%$ of surface resistance was decreased and it indicated that deposited $\mathrm{ZnO}$ film has higher conducting characteristics compared with that of ITO substrate.

\section{ACKNOWLEDGMENTS}

This work was supported by the Korea Science and Engineering Foundation under a grant from the Engineering Research Center for Energy Conversion and Storage.

\section{REFERENCES}

Bohannan, E. W., Huang, L. Y., Miller, F. S., Shumsky, M. G. and Switzer, J. A., "In situ Electrochemical Quartz Crystal Microbalance Study of Potential Oscillations during the Electrodeposition of $\mathrm{Cu} / \mathrm{Cu}_{2} \mathrm{O}$ Layered Nanostructures,' Langmuir, 15, 813 (1999).

Buttary, D. A. and Ward, M. D., "Measurement of Interfacial Processes at Electrode Surfaces with the Electrochemical Quartz Crystal Microbalance,' Chem. Rev., 92, 1355 (1992).

Golden, T. D., Shumsky, M. G., Zhou, Y., VanderWerf, R. A., Van Leeuwen, R. A. and Switzer, J. A., "Electrochemical Deposition of Copper(I) Oxide Films,' Chem. Mater., 8, 2499 (1996).
Gu, Z. H. and Fahidy, T. Z., "Electrochemical Deposition of ZnO Thin Films on Tin-Coated Glasses,' J. Electrochem. Soc., 146, 156 (1999).

Izaki, M. and Katayama, J., "Characterization of Boron-Incorporated Zinc Oxide Film Chemically Prepared from an Aqueous Solution,' J. Electrochem. Soc., 147, 210 (2000).

De Jongh, P. E., Vanmaekelbergh, D. and Kelly, J. J., "Photoelectrochemistry of Electrodeposited $\mathrm{Cu}_{2} \mathrm{O}$,' J. Electrochem. Soc., 147, 486 (2000).

Kim, T. Y., Lee, S. H., Mo, Y. H., Nahm, K. S., Kim, J. Y., Suh, E. K. and Kim, M., "Growth Mechanism of Needle-shaped ZnO Nanostructures over NiO-coated Si Substrates,' Korean J. Chem. Eng., 21, 733 (2004).

Lee, J. and Tak, Y., "The Preparation of Yttrium Oxide Film Deposited by Electrochemical Method,' J. Ind. Eng. Chem., 5, 139 (1999).

Lee, J., Varela, H., Uhm, S. and Tak, Y., "Electrodeposition of $\mathrm{PbO}_{2}$ onto Au and Ti Substrates,' Electrochem. Commun., 2, 646 (2000).

Lee, J. and Tak, Y., "Electrodeposition of ZnO on ITO Electrode by Potential Modulation Method,' Electrochem. Solid-State Lett., 4, C63 (2001).

Lee., J., Noh, T. and Tak, Y., "Electrochemical Deposition of Spherical Shaped $\mathrm{Cu}_{2} \mathrm{O}$ Cluster on Aluminum Electrode,' J. Ind. Eng. Chem., 8, 454 (2002).

Oh, J., Lee, J. and Tak, Y., "Electrodeposition of $\mathrm{Cu}_{2} \mathrm{O}$ Nanowires using Home-made Alumina Template,' Electrochem. Solid-State Lett., 7, C63 (2004).

Suh, Y. W. and Rhee, H. K., "Optimum Washing Conditions for the Preparation of $\mathrm{Cu} / \mathrm{ZnO} / \mathrm{ZrO}_{2}$ for Methanol Synthesis from CO Hydrogenation: Effects of Residual Sodium,' Korean J. Chem. Eng., 19, 17 (2002).

Peulon, S. and Lincot, D., "Mechanistic Study of Cathodic Electrodeposition of Zinc Oxide and Zinc Hydroxychloride Films from Oxygenated Aqueous Zinc Chloride Solutions,' J. Electrochem. Soc., 145, 864 (1998).

Vatistas, N. and Cristofaro, S., "Lead Dioxide Coating Obtained by Pulsed Current Technique,' Electrochem. Commun., 2, 334 (2000).

Wang, Y. G., Lau, S. P., Zhang, X. H., Lee, H. W., Hng, H. H. and Tay, B. K., "Observation of Nitrogen-related Photoluminescence Bands from Nitrogen-doped ZnO Films,' J. Crys. Growth, 252, 265 (2003).

Zheng, M. J., Zhang, L. D., Li, G. H. and Shen, W. Z., "Fabrication and Optical Properties of Large-scale Uniform Zinc Oxide Nanowire Array by One-step Electrochemical Deposition Technique,' Chem. Phys. Lett., 363, 123 (2002). 